Journal of Modern Mathematics and Statistics 4 (1): 22-31, 2010

ISSN: 1994-5388

(C) Medwell Journals, 2010

\title{
An Interactive Stochastic Approach for Solving Stochastic Multi Objective Production Planning Problem
}

\author{
${ }^{1}$ Taghreed A. Hassan and ${ }^{2}$ A.A. Mousa \\ ${ }^{1}$ Department of Basic Engineering Science, Faculty of Engineering, \\ Shebin El-Kom, Minufia University, Egypt \\ ${ }^{2}$ Faculty of Sciences, Al Taif University, Al Taif, KSA
}

\begin{abstract}
In this study, the stochastic production planning involving random variable coefficients and random demand is optimized using an interactive stochastic approach based on reference point satisficing method. This approach combines the concept of probability efficiency for stochastic problems with the reference point method for deterministic multiobjective problems. The decision maker expresses her/his references of each objective and by setting the desired probability for each objective to achieve values belonging to each reference. The proposed approach enable the DM to learn in depth the features of the problem, to evaluate the consequences of each decision and to know the trade-offs between the levels and the probabilities inside each objective function and also among them.
\end{abstract}

Key words: Production planning problem, multi-objective programming, stochastic programming, interactive approach

\section{INTRODUCTION}

In the field of Operations Research (OR), we often encounter real problems in which the Decision Maker (DM) wishes to optimize several objectives at the same time and moreover, does not know the values of some parameters at the moment he or she has to make the decision. When these unknown parameters can be considered as random variables, the resulting problem is denominated in or Stochastic Multi-objective Programming (SMP) problem. The solution of this kind of problem is far from being a trivial task because two of the main hypotheses of classical mathematical programming are relaxed: the values of some of the parameters of the problem are unknown and the Decision Maker (DM) wishes to optimize several conflicting criteria at the same time. Stochastic programming, as an optimization method based on the probability theory have been developed in various ways (Stancu-Minasian, 1984; Slowinski and Teghem, 1990).

Production planning plays a vital role in the management of manufacturing facilities. The production planning problem aims to match production and sourcing decisions to meet future customer demand subject to production capacity, workforce availability and overtime restrictions and is inherently an optimization problem. Production planning process consists of three stages, namely; manufacturing and marketing data preparation, generation of production items and selling alternatives and production plan formulation (Thomas, 2002).

Mathematical models for production planning problems can be broadly classified into two categories: deterministic models and stochastic models. Deterministic models assumes that the data are known and typically model the uncertainty using best guesses of uncertain values (Liu and $\mathrm{Tu}, 2008$ ).

Several uncertainties in manufacturing exist and can be categorized into two categories: environmental uncertainty and system uncertainty. The former refers to uncertainties that are beyond the scope of control of the production process, such as supply and demand uncertainty while the latter refers to uncertainties that relate to the production process, such as operation yield uncertainty, production lead time uncertainty, quality uncertainty and production failures (Mula et al., 2006).

In this study, we focus on Stochastic Multiobjective production planning problem with continuous random variable coefficients in objective functions and constraints. Using the probability maximization model to maximize the probability that each objective function becomes a certain value under chance constrained conditions, the stochastic multi-objective production planning problem is transformed into deterministic one. Assuming that the DM has a stochastic goal for each of

Corresponding Author: Taghreed A. Hassan, Department of Basic Engineering Science, Faculty of Engineering, Shebin El-Kom, Minufia University, Egypt 
the objective functions, having determined the stochastic goals of the DM, we present an interactive reference point satisficing method to derive a satisficing solution for the DM by updating the reference levels which allows the consideration of probabilities given by the DM.

This method combines the concept of probability efficiency for stochastic problems (Prekopa, 1995) with the reference point philosophy for deterministic multi-objective problems. The decision maker expresses her/his references of each objective and by setting the desired probability for each objective to achieve values belonging to each reference. This interactive procedure helps the DM to understand the stochastic nature of the problem, to discover the risk level, he is willing to assume for each objective and to learn about the trade-offs among the objectives.

\section{Preliminaries}

Multi-objective Optimization Preliminaries: Consider the following general $(\mathrm{MOP})$ problem:

$$
\begin{aligned}
& \mathrm{f}_{\mathrm{i}}(\mathrm{x}) \quad \mathrm{i}=1, \ldots, \mathrm{k} \\
& \text { s.t. } \mathrm{x} \in \mathrm{S}
\end{aligned}
$$

Where:

$\mathrm{x}_{\mathrm{i}}=$ Decision variable and denotes a solution

$\mathrm{f}_{\mathrm{i}}(\mathrm{x})=$ Objective functions

$\mathrm{S}=$ The feasible region of the problem

These multiple objectives are usually incommensurate and in conflict with one another because of this, multiple objective optimisation is not to search for optimal solutions but for efficient (non-inferior, non-dominated or Pareto-optimal) solutions that can best attain the prioritised multiple objectives as greatly as possible. Concepts and methods for multiobjective optimization are described by Chankong and Haims (1983).

$\mathrm{x}^{\mathrm{t}}$ is called an efficient (Pareto-optimal) solution of problem 2, if there does not exist any $x \in S\left(x \neq x^{t}\right)$, so that $\mathrm{F}(\mathrm{x}) \leq \mathrm{F}\left(\mathrm{x}^{\mathrm{t}}\right)$ and $\mathrm{F}(\mathrm{x}) \neq \mathrm{F}\left(\mathrm{x}^{\mathrm{t}}\right)$ and $\mathrm{x}^{\mathrm{t}}$ is called a weakly efficient solution of such problem if there does not exist any $x \in S\left(x \neq x^{t}\right)$ so that $F(x)<F\left(x^{t}\right)$, where $f_{i}(i=1, \ldots, k)$ are assumed for minimisation.

\section{MATERIALS AND METHODS}

Multi-objective optimization problems are usually solved by scalarization. It means that the problem is converted into one or a family of single (scalar) objective optimization problems.

This produces a new problem with a real-valued objective function. Solving multi-objective optimization problems usually requires the participation of a human decision maker who is supposed to have better insight into the problem and to express preference relations between alternative solutions. Based on the ways of extracting the decision maker's preference information and using it in decision analysis processes, multiple objective optimisation methods can be divided into three main classes: efficient solution generation methods with preferences provided after optimisation; methods for generating the best compromise solutions based on preferences provided a priori and interactive methods with preferences extracted progressively in decision analysis processes.

Many interactive methods have been developed and their main differences result from the ways of eliciting local preferences and constructing single objective optimisation problems. Since local preference information is relatively easy to provide.

This study is mainly based on Miettinen (1999)'s research. Many researchers have developed various interactive methods for MOP problems are collected (Vincke, 1992).

Interactive reference point method: In order to get a better understanding of the notation used in the interactive method, let us now briefly describe some terms used in the reference point-based interactive methods for deterministic multi-objective problems.

The reference point method (Wierzbicki, 1980) is based on vectors formed of reasonable or desirable aspiration levels. These reference points are used to derive scalarizing functions having minimal solutions at weakly, properly or Pareto optimal points. Let us consider problem 1:

Given a vector $\overline{\mathrm{f}}_{\mathrm{i}}^{*}, \mathrm{i}=1, \ldots, \mathrm{k}$ of reference levels for each objective and a vector of strictly positive weights $\mathrm{w}_{\mathrm{i}}, \mathrm{i}=$ $1 \ldots, \mathrm{k}$, the achievement scalarizing function defined by Wierzbicki (1977) is the following:

$$
\begin{aligned}
& \text { minimize } \max _{\substack{i=1, \ldots, k \\
\text { Subject to }}} \mathrm{x} \in \mathrm{S} \\
& \text { S }
\end{aligned}
$$

or equivalently by solving the following problem:

$$
\begin{aligned}
& \operatorname{Min}_{\mathrm{x}, \alpha} \alpha \\
& \text { S.t. } \mathrm{w}_{\mathrm{i}}\left(\mathrm{f}_{\mathrm{i}}(\mathrm{x})-\overline{\mathrm{f}}_{\mathrm{i}}^{*}\right) \leq \alpha, \quad \mathrm{i}=1, \ldots, \mathrm{k} \\
& \mathrm{x} \in \mathrm{S}
\end{aligned}
$$

An optimal solution to problem 2 with the achievement scalarizing function $\mathrm{s}$ is weakly efficient for 
(MOP) (and efficient if it is unique) (Miettinen, 1999). Some other achievement scalarizing functions have been defined in the literature. Each of them has its own particularities and drawbacks. An overview of these functions can be found by Miettinen and Makela (2002).

Stochastic multiobjective preliminaries: The following stochastic multiobjective programming problem will be considered in this study:

$$
\begin{aligned}
& \operatorname{Min}\left(\tilde{z}_{1}(x, \tilde{\omega}), \tilde{z}_{2}(x, \tilde{\omega}), \ldots, \tilde{z}_{\mathrm{k}}(\mathrm{x}, \tilde{\omega})\right) \\
& \text { S.t. } \tilde{\mathrm{g}}_{\mathrm{i}}(\mathrm{x}, \tilde{\omega}) \leq 0, \quad \mathrm{i}=1, \ldots, \mathrm{m} \\
& \mathrm{x} \in \mathrm{S}
\end{aligned}
$$

Where:

$\mathrm{x} \in \mathrm{R}^{\mathrm{n}}=$ The vector of decision variables of the problem

$\tilde{\omega}=$ Random vector whose components are continuous random variables defined on the set $\mathrm{E} \subset \mathrm{R}^{\mathrm{S}}$

It will be assumed that given the family $\mathrm{F}$ of events that is $\mathrm{F} \subset \mathrm{E}$, the probability distribution $\mathrm{P}$ defined on $\mathrm{F}$ is known, i.e., for any $A \in F$, the probability of $A ., P(A)$ is known. It will also be assumed that the probability distribution, $P$ is independent of the decision variables $\mathrm{x}_{1}, \ldots \mathrm{x}_{\mathrm{n}}$. Functions $\tilde{\mathrm{z}}_{1}(\mathrm{x}, \tilde{\omega}), \tilde{\mathrm{z}}_{2}(\mathrm{x}, \tilde{\omega}), \ldots, \tilde{\mathrm{z}}_{\mathrm{k}}(\mathrm{x}, \tilde{\omega})$ are stochastic objectives defined on $\mathrm{R}^{\mathrm{n}} \mathrm{x}$ E. Functions $\tilde{\mathrm{g}}_{\mathrm{i}}(\mathrm{x}, \tilde{\omega})$ are stochastic constraints with $i=1, \ldots \ldots ., \mathrm{m}$.

Since the stochastic constraint do not define a deterministic feasible set, it is desired that the stochastic constraints hold with a confidence level $\beta$. Thus we have a chance constraint as follows:

$$
\mathrm{P}\left(\widetilde{\mathrm{g}}_{\mathrm{i}}(\mathrm{x}, \tilde{\omega}) \leq 0\right) \geq \beta_{\mathrm{i}}, \quad \mathrm{i}=1, \ldots, \mathrm{m}
$$

A point $\mathrm{x}$ is called feasible if and only if the probability measure of the event $(\tilde{\mathrm{g}}(\mathrm{x}, \tilde{\omega}) \leq 0)$ is at least $\beta$ (Liu, 2008). In other words, the constraints will be violated at most $(1-\beta)$ of time.

Deterministic equivalents: The basic idea in the solution of any problem of stochastic programming is to transform the stochastic problem into an equivalent deterministic problem; equivalent in the sense that a solution for the corresponding deterministic problem is a solution for the stochastic problem. Thus, the equivalent deterministic problem can be solved by using some familiar technique of linear, geometric, dynamic or non-linear programming. Let us consider the following form of chance constraint:

$$
\mathrm{P}(\tilde{\mathrm{g}}(\mathrm{x}, \tilde{\omega}) \leq 0) \geq \beta
$$

Theorem: Liu (2008) assume that the stochastic vector $\omega$ degenerates to a random variable $\omega$ with probability distribution $\Phi$ and the function $\mathrm{g}(\mathrm{x}, \omega)$ has the form $\mathrm{g}(\mathrm{x}, \omega)=\mathrm{h}(\mathrm{x})-\omega$. Then $\operatorname{Pr}\{\mathrm{g}(\mathrm{x}, \omega) \leq 0\} \geq \beta$ if and only if $\mathrm{h}(\mathrm{x}) \leq \mathrm{K}_{\beta}$, where $\mathrm{K}_{\beta}$ is the maximal number such that:

$$
\operatorname{Pr}\left\{K_{\beta} \leq \omega\right\} \geq \beta
$$

Remark: For a continuous random variable $\omega$, the equation;

$$
\operatorname{Pr}\left\{\mathrm{K}_{\beta} \leq \omega\right\}=1-\Phi\left(\mathrm{K}_{\beta}\right)
$$

always holds and we have Eq. 6 :

$$
\mathrm{K}_{\beta}=\Phi^{-1}(1-\beta)
$$

where $\Phi^{-1}$ is the inverse function of $\Phi$.

Theorem: Liu (2008) assume that the stochastic vector $\omega=\left(a_{1}, a_{2}, \ldots, a_{n}, b\right)$ and the function $g(x, \omega)$ has the form:

$$
g(x, \omega)=a_{1} x_{1}+a_{2} x_{2}+\ldots+a_{n} x_{n}-b
$$

If $a_{i}$ and $b$ are assumed to be independently normally distributed variables, then;

$$
\operatorname{pr}\{\mathrm{g}(\mathrm{x}, \omega) \leq 0\} \geq \beta
$$

if and only if;

$$
\sum_{i=1}^{n} E\left[a_{i}\right] x_{i}+\Phi^{-1}(\beta) \sqrt{\sum_{i=1}^{n} V\left[a_{i}\right] x_{i}^{2}+V[b]} \leq E[b]
$$

where $\Phi$ is the standardized normal distribution.

Problem formulation for production planning: Consider a production planning problem to optimize the gross profit and production cost simultaneously under the condition that unit profits of the products, unit production costs of them and maximal amounts of the resources depend on seasonal factors or market prices. Product demand is one of the key inputs and a major source of uncertainty to a production planning problem.

As such, developing stochastic production planning that accounts for demand uncertainty is necessary for effectively running a production facility and to deal with any specific realization of the demand uncertainty. Such production planning problem can be formulated as a multi-objective programming problem with random variable coefficients expressed by the following problem: 


$$
\begin{array}{cc}
\text { minimize } & z_{1}(x, \omega)=c_{1}(\omega) x+\alpha_{1}(\omega) \\
& \vdots \\
\text { minimize } & z_{k}(x, \omega)=c_{k}(\omega) x+\alpha_{k}(\omega) \\
\text { subject to } & A x \leq b(\omega), \\
& x \geq 0
\end{array}
$$

Where:

$$
\begin{aligned}
& \mathrm{z}_{\mathrm{i}, \mathrm{i}=1, . ., \mathrm{k}=} \begin{array}{l}
\text { Objective functions to be optimized. } \\
\mathrm{x}
\end{array}=\begin{array}{l}
\text { Such as gross profit and production cost } \\
\text { The vectore of decision variables whose } \\
\text { optimal value is not conditioned on } \\
\text { realization of the uncertain parameters. } \\
\text { These are design variables (production } \\
\text { item) for which the problem solved }
\end{array} \\
& \mathrm{c}(\omega)+\alpha(\omega)=\begin{array}{l}
\text { Random variable coefficient due to } \\
\text { random cost }
\end{array}=\begin{array}{l}
\text { Coefficient measuring the effect of the } \\
\text { constraint on the decision variable }
\end{array} \\
& \mathrm{b}(\omega)=\begin{array}{l}
\text { Random variable right hand side of the } \\
\text { constraint due to random demand }
\end{array}
\end{aligned}
$$

An interactive stochastic approach based on Reference point satisficing method through Probability maximization model

Main features: First, let us introduce some of the basic ideas of the algorithm which are based on the previous comments. The first step consists in the transformation of the problem into an equivalent deterministic problem by choosing one of the existing transformation criteria.

An efficient solution to this deterministic problem is regarded as efficient for the original stochastic one. For this algorithm, the concept of probability maximization model has been chosen. Since the problem 9 contains random variable coefficients, definitions and solution methods for ordinary mathematical programming problems cannot be directly applied. Consequently, we deal with the constraints in problem 9 as chance constrained conditions (Charnes and Cooper, 1959) which mean that the constraints need to be satisfied with a certain probability (satisficing level).

Using the probability maximization model to maximize the probability that each objective function becomes a certain value under the chance constrained conditions, the stochastic programming problems are transformed into deterministic ones. Assuming that the DM has a stochastic goal for each of the objective functions, having determined the stochastic goals of the DM, researchers present an interactive reference point satisficing method to derive a satisficing solution for the DM by updating the reference levels. Assume that the constraints in problem 9 are in the form $A x \leq b_{i}(\omega)$, where $x$ is an $n$ dimensional decision variable column vector and $\mathrm{A}$ is an mxn coefficient matrix and $b_{i}(\omega)$ are random variables independent of each other. Replacing these constraints by chance constrained conditions with satisficing levels $\beta_{i}, i=1, \ldots ., m$ along with substituting the minimization of the objective functions $Z_{1}(\mathrm{x}, \varpi), 1=1, \ldots, \mathrm{k}$ in problem 9 for the maximization of the probability that each of objective functions $Z_{1}(x, \varpi)$ is less than or equal to a certain permissible level $\mathrm{u}_{1}$, the problem can be converted as:

$$
\begin{array}{rlrl}
\operatorname{maximize} & \mathrm{P}_{1}(\mathrm{x}) & =\operatorname{Pr}\left[\mathrm{Z}_{1}(\mathrm{x}, \tilde{\omega}) \leq \mathrm{u}_{1}\right] \\
& \vdots \\
\text { maximize } & \mathrm{P}_{\mathrm{k}}(\mathrm{x}) & =\operatorname{Pr}\left[\mathrm{Z}_{\mathrm{k}}(\mathrm{x}, \tilde{\omega}) \leq \mathrm{u}_{\mathrm{k}}\right]
\end{array}
$$

subject to

$$
\begin{aligned}
& \operatorname{Pr}\left[\mathrm{a}_{1} \mathrm{x} \leq \mathrm{b}_{1}(\mathrm{w})\right] \geq \beta_{1}, \\
& \vdots \\
& \operatorname{Pr}\left[\mathrm{a}_{\mathrm{m}} \mathrm{x} \leq \mathrm{b}_{\mathrm{m}}(\mathrm{w})\right] \geq \beta_{\mathrm{m}}, \\
& \mathrm{x} \geq 0
\end{aligned}
$$

where $a_{i}$ is the ith row vector of $A$ and $b_{i}(\omega)$ is the ith element of $b(\omega)$. Denoting distribution functions of random variables $b_{i}(\omega), i=1, \ldots, m$ by:

$$
\mathrm{F}_{\mathrm{i}}(\mathrm{r})=\operatorname{Pr}\left[\mathrm{b}_{\mathrm{i}}(\varpi) \leq \mathrm{r}\right]
$$

the ith constraint in Eq. 10 can be rewritten as:

$$
\begin{aligned}
\operatorname{Pr}\left[\mathrm{a}_{\mathrm{i}} \mathrm{x} \leq \mathrm{b}_{\mathrm{i}}(\mathrm{w})\right] \geq & \beta_{\mathrm{i}} \Leftrightarrow 1-\operatorname{Pr}\left[\mathrm{b}_{\mathrm{i}}(\mathrm{w}) \leq \mathrm{a}_{\mathrm{i}} \mathrm{x}\right] \\
& \geq \beta_{\mathrm{i}} \Leftrightarrow 1-\mathrm{F}_{\mathrm{i}}\left(\mathrm{a}_{\mathrm{i}} \mathrm{x}\right) \geq \beta_{\mathrm{i}} \\
& \Leftrightarrow \mathrm{F}_{\mathrm{i}}\left(\mathrm{a}_{\mathrm{i}} \mathrm{x}\right) \leq 1-\beta_{\mathrm{i}} \\
& \Leftrightarrow \mathrm{a}_{\mathrm{i}} \mathrm{x} \leq \mathrm{F}_{\mathrm{i}}^{-1}\left(1-\beta_{\mathrm{i}}\right)
\end{aligned}
$$

Where $\mathrm{F}_{\mathrm{i}}^{-1}$ (.) means a pseudo-inverse function corresponding to $\mathrm{F}_{\mathrm{i}}($.) defined as:

$$
\mathrm{F}_{\mathrm{i}}(\mathrm{h})=\inf \left\{\mathrm{y} \mid \mathrm{F}_{\mathrm{i}}(\mathrm{y}) \geq \mathrm{h}\right\}
$$

Let $\hat{b}_{i}=F_{i}^{-1}\left(1-\beta_{i}\right)$ then, the problem 10 can be transformed into the following equivalent problem:

$$
\begin{array}{cc}
\text { maximize } & \mathrm{P}_{1}(\mathrm{x})=\operatorname{Pr}\left[\mathrm{Z}_{1}(\mathrm{x}, \tilde{\omega}) \leq \mathrm{u}_{1}\right] \\
& \vdots \\
\text { maximize } & \mathrm{P}_{\mathrm{k}}(\mathrm{x})=\operatorname{Pr}\left[\mathrm{Z}_{\mathrm{k}}(\mathrm{x}, \widetilde{\omega}) \leq \mathrm{u}_{\mathrm{k}}\right] \\
\text { subject to, } & \\
& \mathrm{Ax} \leq \hat{\mathrm{b}}_{\mathrm{i}}, \\
& \mathrm{x} \geq 0
\end{array}
$$


Let the feasible region of problem 12 is denoted by S. After transforming the (SMP) problem in the form of maximum probability model, the DM has to fix a value $\mathrm{u}$ (aspiration level of the problem's objective function involving random variables with a given (known) probability distribution).

In deterministic reference point-based algorithms, the DM has to give reference values for each objective. But in stochastic multio-bjective problems giving a single value can be misleading, given that the objectives will not reach a certain value and there is a trade-off between the risk assumed and the level achieved by the objective function. The election between two efficient solutions with different probabilities will depend on the risk level that the DM is willing to assume.

The aim now is to help the decision maker to understand the stochastic nature of the problem, to discover the risk level, he is willing to assume for each objective to fix aspiration level of the problem's objective function involving random variables with a given probability distribution and to learn about the trade-offs among the objectives. The process begins by obtaining an approximate variation range for each stochastic objective. Hence, we will ask the DM to fix a confidence interval $\left(\beta_{\mathrm{L}}, \beta_{\mathrm{U}}\right)$ for each objective function as; calculate the values $L_{i}$ and $U_{i}$, such that:

$$
\begin{aligned}
& \operatorname{Pr}\left[Z_{i}(x, \tilde{\omega}) \leq L_{i}\right]=\beta_{L}, \operatorname{Pr}\left[Z_{i}(x, \tilde{\omega}) \leq U_{i}\right]=\beta_{U}, i=1, \ldots, k \\
& {\left[L_{i}, U_{i}\right] \mid \operatorname{Pr}\left[L_{i} \leq Z_{i}(x, \tilde{\omega}) \leq U_{i}\right]=\left(\beta_{U}-\beta_{L}\right), i=1, \ldots, k}
\end{aligned}
$$

This way, the solution obtained is assured to be probability efficient and we leave room to select the stochastic range of the objectives. That is why we will solve the stochastic approach developed by Caballero et al. (2004), subject to the feasible region defined in Eq. 12 as follow:

Where:

$$
\begin{aligned}
& \underset{\mathrm{z}, \mathrm{u}}{\operatorname{Min}} \mathrm{u} \\
& \text { S.t. } \mathrm{P}\left(\sum_{\mathrm{i}=1}^{\mathrm{k}} \mathrm{u}_{\mathrm{i}} \tilde{\mathrm{Z}}_{\mathrm{i}}(\mathrm{x}, \tilde{\omega}) \leq \mathrm{u}\right)=\beta, \\
& \mathrm{x} \in \mathrm{S}
\end{aligned}
$$

and the weights $\mu_{\mathrm{i}} \succ 0$ and;

$$
\sum_{i=1}^{k} \mu_{i}=1
$$

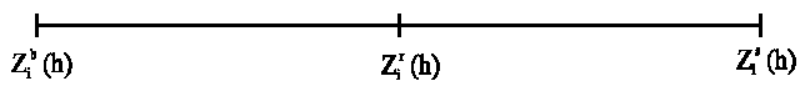

Fig. 1: The subintervales of the stochastic objectives

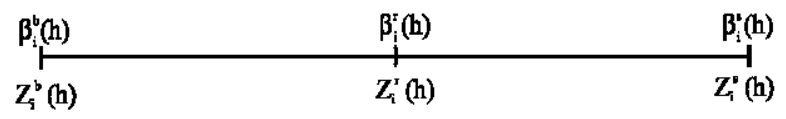

Fig. 2: The probabilities of the corresponding objective

$\mu_{\mathrm{i}}$ takes various values as $o<\mu_{\mathrm{i}}<1$, then a set of efficient solutions of problem 13 will be obtained. This way, the DM knows many approximate variation range for each stochastic objective. Then, the DM is asked to fix a worst value, $Z_{i}^{\mathrm{s}}(\mathrm{h})$ and a best value, $Z_{i}{ }^{b}(h)$ for each objective and $Z_{i}^{r}(h)$ intermediate values. This way, the variation range of the stochastic objective is divided into subintervals, as shown in Fig. 1. Based on the previous information, the expected value efficiency criterion, subject to the feasible region defined in problem 12 to obtain an intial solution will be solved as follow:

$$
\begin{aligned}
& \operatorname{Min}_{\mathrm{z}, \alpha} \alpha \\
& \text { S.t. } \mu_{\mathrm{i}}\left(\bar{Z}_{\mathrm{i}}(\mathrm{x})-\overline{\mathrm{Z}}_{\mathrm{i}}^{*}\right) \leq \alpha, \quad \mathrm{i}=1, \ldots, \mathrm{k} \\
& \quad \mathrm{x} \in \mathrm{S}
\end{aligned}
$$

where $\bar{Z}_{i}^{*}$ is the expected value of the ith stochastic objective and the weights;

$$
\mu_{\mathrm{i}}=\frac{1}{Z_{\mathrm{imax}}-Z_{\mathrm{imin}}}, \mathrm{i}=1, \ldots, \mathrm{k}
$$

are obtained from the payoff matrix corresponding to the expected value equivalent deterministic multi-objective problem that is;

$$
\overline{\mathrm{Z}}_{\mathrm{i}}^{*}=\operatorname{Min}_{\mathrm{z} \in \mathrm{S}}\left(\overline{\mathrm{Z}}_{\mathrm{i}}(\mathrm{x})\right), \quad \mathrm{i}=1, \ldots, \mathrm{k}
$$

then for each objective, the algorithm calculates the accumulated probability corresponding to each value fixed by the DM, as shown in Fig. 2:

$$
\operatorname{Pr}\left(Z_{\mathrm{i}}\left(\mathrm{x}^{\mathrm{h}}, \widetilde{\omega}\right) \leq \mathrm{Z}_{\mathrm{i}}^{\mathrm{r}}(\mathrm{h})\right)=\beta_{\mathrm{i}}^{\mathrm{r}}(\mathrm{h}), \quad(\mathrm{i}=1, \ldots, \mathrm{k})
$$

For each $\mathrm{i}=1, \ldots ., \mathrm{k}$, the $\mathrm{DM}$ is shown the probabilities of the corresponding objective in the current solution. If the DM is satisfied with the current objective values, then $\mathrm{x}^{\mathrm{h}}$ is the final solution. Otherwise, he asked to indicate the new desired accumulated probabilities for some values $\mathrm{Z}_{\mathrm{i}}^{\mathrm{r}}(\mathrm{h})$. Let $\mathrm{D}^{\mathrm{h}}$ the set of indexes corresponding to the objectives that the DM wishes to change. 
For each $i \in D^{h}$, let $S_{i}^{h}$ be the set of indexes corresponding to the values $Z_{i}^{\mathrm{r}}(\mathrm{h})$ of objective $i$ for which the DM wishes to change the probability. $\beta_{i}^{r}(h)$ be the new probability assigned to $Z_{i}^{\mathrm{r}}(\mathrm{h}), \mathrm{r} \in \mathrm{S}_{\mathrm{i}}^{\mathrm{h}}$.

Therefore, once the new information is provided, the following problem is solved, where the reference point philosophy for deterministic problems is adapted to the (SMP) problem:

$$
\begin{array}{lll}
\text { Min } & \alpha & \\
\text { s.t. } & \mu_{i}^{\mathrm{h}} \cdot\left(\overline{\mathrm{Z}}_{\mathrm{i}}(\mathrm{x})-\mathrm{Z}_{\mathrm{i}}^{\mathrm{x}}(\mathrm{h})\right) \leq \alpha, & \forall \mathrm{r} \in \mathrm{S}_{\mathrm{i}}^{\mathrm{h}}, \quad \mathrm{i} \in \mathrm{D}^{\mathrm{h}}, \\
& \operatorname{Pr}\left(\tilde{\mathrm{Z}}_{\mathrm{i}}(\mathrm{x}, \tilde{\omega}) \leq \mathrm{u}_{\mathrm{i}}^{\mathrm{x}}\right) \geq \beta_{\mathrm{i}}^{\mathrm{x}}(\mathrm{h}), \quad \forall \mathrm{r} \in \mathrm{S}_{\mathrm{i}}^{\mathrm{h}}, \quad \mathrm{i} \in \mathrm{D}^{\mathrm{h}}, \\
& \mu_{\mathrm{k}} \cdot\left(\overline{\mathrm{Z}}_{\mathrm{i}}(\mathrm{x})-\mathrm{Z}_{\mathrm{i}}^{\mathrm{s}}(\mathrm{h})\right) \leq \alpha, & \mathrm{i} \notin \mathrm{D}^{\mathrm{h}}, \\
& \operatorname{Pr}\left(\tilde{\mathrm{Z}}_{\mathrm{i}}(\mathrm{x}, \tilde{\omega}) \leq \mathrm{u}_{\mathrm{i}}^{\mathrm{s}}\right) \geq 0.5, & \mathrm{i} \notin \mathrm{D}^{\mathrm{h}}, \\
& \mathrm{x} \in \mathrm{S}
\end{array}
$$

Where:

$\mathrm{D}^{\mathrm{h}}=\quad$ The set of indexes corresponding to the objectives that the DM wishes to change, for each $I \in D^{h}$

$\mathrm{S}_{\mathrm{i}}^{\mathrm{h}}=\quad$ The set of indexes corresponding to the values $Z_{i}^{r}(h)$ of objective $i$ for which the DM wishes change to the probabilities

$\beta_{i}^{\mathrm{r}}(\mathrm{h}) \quad=$ The new probability assigned to $\mathrm{Z}_{\mathrm{i}}^{\mathrm{r}}(\mathrm{h})$

$$
\mu_{i}^{h}=\frac{1}{Z_{i}^{s}(h)-Z_{i}^{b}(h)}
$$

that is the difference between the worst and best values given by the DM is used as the normalizing factor. The process goes on until a solution accepted by the DM is found. Let us now describe the proposed interactive algorithm step by step.

\section{Step-by-step description of the proposed approach}

Step 1: Ask the decision maker to specify the satisficing levels $\beta_{i}, i=1, \ldots \ldots, m$ for each of the constraints in problem 10 .

Step 2: The algorithm transform problem 10 into the equivalent problem 12 .

Step 3: Ask the DM to fix a confidence interval $\left(\beta_{\mathrm{L}}, \beta_{\mathrm{U}}\right)$ for each objective function with these informations, solve problem 13 to obtain an approximate variation range for each stochastic objective and show these variation range (th) the DM:

$$
\left[\mathrm{L}_{\mathrm{i}}, \mathrm{U}_{\mathrm{i}}\right] \mid \operatorname{Pr}\left[\mathrm{L}_{\mathrm{i}} \leq \mathrm{Z}_{\mathrm{i}}(\mathrm{x}, \tilde{\omega}) \leq \mathrm{U}_{\mathrm{i}}\right]=\left(\beta_{\mathrm{U}}-\beta_{\mathrm{L}}\right), \mathrm{i}=1, \ldots, \mathrm{k}
$$

Step 4: Ask the DM to fix a worst value, $Z_{i}^{s}(h)$ and a best value, $Z_{i}^{b}(h)$ and $Z_{i}^{r}(h)$ for each objective.

Step 5: Solve problem 14 to obtain a solution.

Step 6: With this solution the algorithm calculates the accumulated probability corresponding to each value fixed by the DM,

$$
\operatorname{Pr}\left(Z_{\mathrm{i}}\left(\mathrm{x}^{\mathrm{h}}, \tilde{\omega}\right) \leq \mathrm{Z}_{\mathrm{i}}^{\mathrm{r}}(\mathrm{h})\right)=\beta_{\mathrm{i}}^{\mathrm{r}}(\mathrm{h}), \quad(\mathrm{i}=1, \ldots, \mathrm{k})
$$

The DM is shown the probabilities of the corresponding objective at the current solution. Let $\mathrm{h}=0$.

Step 7: Ask the DM if he satisfied with the current objective values, then stop. Otherwise continue.

Step 8: If the DM desires to change the scale, then go to step 4.

Step 9: Ask the DM to indicate the new desired accumulated probabilities for some values $Z_{1}^{r}(h)$.

Step 10: Solve problem 15 to obtain a new solution solution. Let $\mathrm{h}=\mathrm{h}+1$. Go to step 6 .

The process goes on until a solution accepted by the $\mathrm{DM}$ is found.

\section{RESULTS AND DISCUSSION}

Consider the following production planning problem involving random variable coefficients ( 3 objectives, 10 variables, 7 constraints):

$$
\begin{array}{ll}
\operatorname{minimize} & \left(\mathrm{c}_{1}^{1}+\mathrm{t}_{1}(\mathrm{w}) \mathrm{c}_{1}^{2}\right) \mathrm{x}+\left(\alpha_{1}^{1}+\mathrm{t}_{1}(\mathrm{w}) \alpha_{1}^{2}\right) \\
\text { minimize } & \left(\mathrm{c}_{2}^{1}+\mathrm{t}_{2}(\mathrm{w}) \mathrm{c}_{2}^{2}\right) \mathrm{x}+\left(\alpha_{2}^{1}+\mathrm{t}_{2}(\mathrm{w}) \alpha_{2}^{2}\right) \\
\text { minimize } & \left(\mathrm{c}_{3}^{1}+\mathrm{t}_{3}(\mathrm{w}) \mathrm{c}_{3}^{2}\right) \mathrm{x}+\left(\alpha_{3}^{1}+\mathrm{t}_{3}(\mathrm{w}) \alpha_{3}^{2}\right)
\end{array}
$$

subject to;

$$
\begin{aligned}
& a_{1} x \leq b_{1}(w), \\
& a_{2} x \leq b_{2}(w), \\
& a_{3} x \leq b_{3}(w), \\
& a_{4} x \leq b_{4}(w), \\
& a_{5} x \leq b_{5}(w), \\
& a_{6} x \leq b_{6}(w), \\
& a_{7} x \leq b_{7}(w), \\
& x \geq 0
\end{aligned}
$$


J. Modern Mathe. Stat., 4 (1): 22-31, 2010

\begin{tabular}{|c|c|c|c|c|c|c|c|c|c|c|c|c|}
\hline$\overline{c_{1}{ }^{1}}$ & 19 & 48 & 21 & 10 & 18 & 35 & 46 & 11 & 24 & 33 & $\mathrm{a}_{1}{ }^{1}$ & -18 \\
\hline$c_{1}{ }^{2}$ & 32 & 21 & 4 & 3 & 1 & 2 & 4 & 2 & $a_{1}^{2}$ & 5 & & \\
\hline $\mathrm{c}_{2}{ }^{1}$ & 12 & -46 & -23 & -38 & -33 & -48 & 12 & 8 & 19 & 20 & $\mathrm{a}_{2}{ }^{1}$ & -27 \\
\hline$c_{2}{ }^{2}$ & 12 & 42 & 2 & 1 & 2 & 1 & 2 & 1 & $\mathrm{a}_{2}{ }^{2}$ & 6 & & \\
\hline$c_{3}{ }^{1}$ & -18 & -26 & -22 & -28 & -15 & -29 & -10 & -19 & -17 & -28 & $\mathrm{a}_{3}{ }^{1}$ & -10 \\
\hline $\mathrm{c}_{3}{ }^{2}$ & 21 & 32 & 1 & 2 & 3 & 3 & 2 & 1 & $\mathrm{a}_{3}{ }^{2}$ & 4 & & \\
\hline
\end{tabular}

Table 2: Constant coefficients of constraints in 16

\begin{tabular}{|c|c|c|c|c|c|c|c|c|c|c|}
\hline$a_{1}$ & 12 & -2 & 4 & -7 & 13 & -1 & -6 & 6 & 11 & -8 \\
\hline$a_{2}$ & -2 & 5 & 3 & 16 & 6 & -12 & 12 & 4 & -7 & -10 \\
\hline$a_{3}$ & 3 & -16 & -4 & -8 & -8 & 2 & -12 & -12 & 4 & -3 \\
\hline$a_{4}$ & -11 & 6 & -5 & 9 & -1 & 8 & -4 & 6 & -9 & 6 \\
\hline$a_{5}$ & -4 & 7 & -6 & -5 & 13 & 6 & -2 & -5 & 14 & -6 \\
\hline $\mathrm{a}_{6}$ & 5 & -3 & 14 & -3 & -9 & -7 & 4 & -4 & -5 & 9 \\
\hline$\underline{\mathrm{a}_{7}}$ & -3 & -4 & -6 & 9 & 6 & 18 & 11 & -9 & -4 & 7 \\
\hline
\end{tabular}

In this problem, $\mathrm{t}_{\mathrm{i}}(\mathrm{w}), \mathrm{t}_{2}(\mathrm{w})$ and $\mathrm{t}_{3}(\mathrm{w})$ are Gaussian random variables. $\mathrm{N}\left(4,2^{2}\right), \mathrm{N}\left(3,3^{2}\right)$ and $\mathrm{N}\left(3,2^{2}\right)$, where $\mathrm{N}\left(\alpha, \beta^{2}\right)$ stands for a Gaussian random variable having mean $\alpha$ and variance $\beta^{2}$.

The right-hand side $b_{i}(w), i=1, \ldots, 7$ are also Gaussian random variables $\mathrm{N}\left(164,30^{2}\right), \mathrm{N}\left(-190,20^{2}\right), \mathrm{N}\left(-184,15^{2}\right)$, $\mathrm{N}\left(99,22^{2}\right), \mathrm{N}\left(-150,17^{2}\right), \mathrm{N}\left(154,35^{2}\right), \mathrm{N}\left(142,28^{2}\right)$. On the other hand, constant coefficients in the problem are shown in Table 1 and 2.

According to step 1, the DM fixes the satisficing levels $\beta_{\mathrm{i}}, \mathrm{i}=1,2, \ldots, 7$ for each of the constraints in problem 16.

The hypothetical DM in this example specifies the satisficing levels as $\left(\beta_{1}-\beta_{7}\right)^{\mathrm{T}}=(0.85,0.95,0.8,0.9,0.85,0.8$, $0.9)^{\mathrm{T}}$, respectively.

The process begins by obtaining the following confidence intervals for each objective, assuming that the DM wants a $90 \%$ confidence intervals :

$$
\begin{gathered}
\mathrm{P}\left(1564.15 \leq \tilde{\mathrm{Z}}_{1}(\mathrm{x}) \leq 2567.87\right)=0.9 \\
\mathrm{P}\left(115.1 \leq \tilde{\mathrm{Z}}_{2}(\mathrm{x}) \leq 832.6\right)=0.9 \\
\mathrm{P}\left(-1433.19 \leq \tilde{\mathrm{Z}}_{3}(\mathrm{x}) \leq-640.82\right)=0.9
\end{gathered}
$$

Given this information, the DM is asked to establish the subintervals.

Let us suppose that the DM divides each range into negative subintervals of equal length (very poor, poor, fair, good and very good), the individual minimum $\bar{z}_{\mathrm{i}}^{*}, \mathrm{i}=1,2,3$ of the expected value for each objective functions are calculated under the chance constrained conditions corresponding to the satisficing levels. By solving the following problem:
Minimize $\mathrm{E}\left(\mathrm{Z}_{1}\left(\mathrm{x}, \tilde{\mathrm{c}}_{1}(\mathrm{w})\right)\right), \quad 1=1,2,3$

subject to;

$$
\begin{aligned}
& \mathrm{P}\left(\mathrm{a}_{1} \mathrm{x} \leq \tilde{\mathrm{b}}_{1}(\mathrm{w})\right) \geq \beta_{1}, \\
& \mathrm{P}\left(\mathrm{a}_{2} \mathrm{x} \leq \tilde{\mathrm{b}}_{2}(\mathrm{w})\right) \geq \beta_{2}, \\
& \mathrm{P}\left(\mathrm{a}_{3} \mathrm{x} \leq \tilde{\mathrm{b}}_{3}(\mathrm{w})\right) \geq \beta_{3}, \\
& \mathrm{P}\left(\mathrm{a}_{4} \mathrm{x} \leq \tilde{\mathrm{b}}_{4}(\mathrm{w})\right) \geq \beta_{4}, \\
& \mathrm{P}\left(\mathrm{a}_{5} \mathrm{x} \leq \tilde{\mathrm{b}}_{5}(\mathrm{w})\right) \geq \beta_{5}, \\
& \mathrm{P}\left(\mathrm{a}_{6} \mathrm{x} \leq \tilde{\mathrm{b}}_{6}(\mathrm{w})\right) \geq \beta_{6}, \\
& \mathrm{P}\left(\mathrm{a}_{7} \mathrm{x} \leq \tilde{\mathrm{b}}_{7}(\mathrm{w})\right) \geq \beta_{7}, \\
& \mathrm{P}\left(\mathrm{a}_{8} \mathrm{x} \leq \tilde{\mathrm{b}}_{8}(\mathrm{w})\right) \geq \beta_{8}, \\
& \mathrm{x} \geq 0
\end{aligned}
$$

Each value is obtained as:

$$
\overline{\mathrm{Z}}_{1}^{*}=1819.62, \overline{\mathrm{Z}}_{2}^{*}=252.52, \overline{\mathrm{Z}}_{3}^{*}=-1121.26
$$

Taking the expected values of each objective function as:

$$
\overline{\mathrm{F}}_{1}^{*}=1819.62, \overline{\mathrm{F}}_{2}^{*}=252.52, \overline{\mathrm{F}}_{3}^{*}=-1121.26
$$

The reference levels and weights:

$$
\begin{gathered}
\mu l=\frac{1}{f_{\max }-f_{\min }}, 1=1,2,3 \\
\mu 1=\frac{1}{581.28}, \mu 2=\frac{1}{523.665}, \mu 3=\frac{1}{200}
\end{gathered}
$$

with these data, solve problem 14. The first solution shown to the $\mathrm{DM}$ is $\mathrm{x}^{0}=(15.96,1.662,0,1.2,0,6.67,0.518$, $14.122,2.36,18.47)^{\mathrm{T}}$ next the algorithm obtains the probabilities associated to these intervals at the current solution. These data are shown in Fig. 3. 

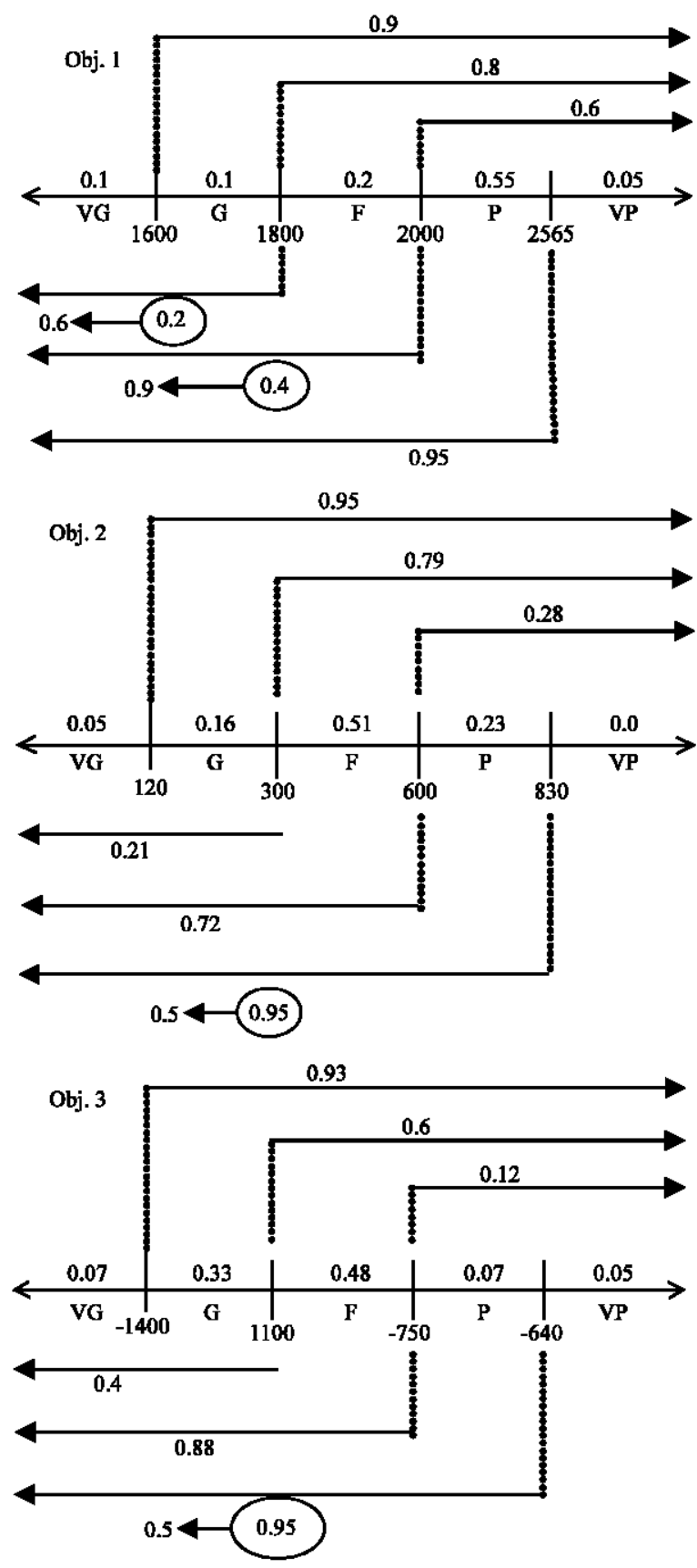

Fig. 3: Intial solution of the problem

Assume that the DM wants to improve the probability for the first objective to be fair, good and very good, while he allows to impair objective 2 and 3 by setting the following probabilities (Fig. 3):

\section{Objective 1:}

$$
\mathrm{P}\left(\tilde{\mathrm{f}}_{1}(\mathrm{x}, \mathrm{c}) \leq 1800\right) \geq 0.6 \text { and } \mathrm{P}\left(\tilde{\mathrm{f}}_{1}(\mathrm{x}, \mathrm{c}) \leq 2000\right) \geq 0.9
$$
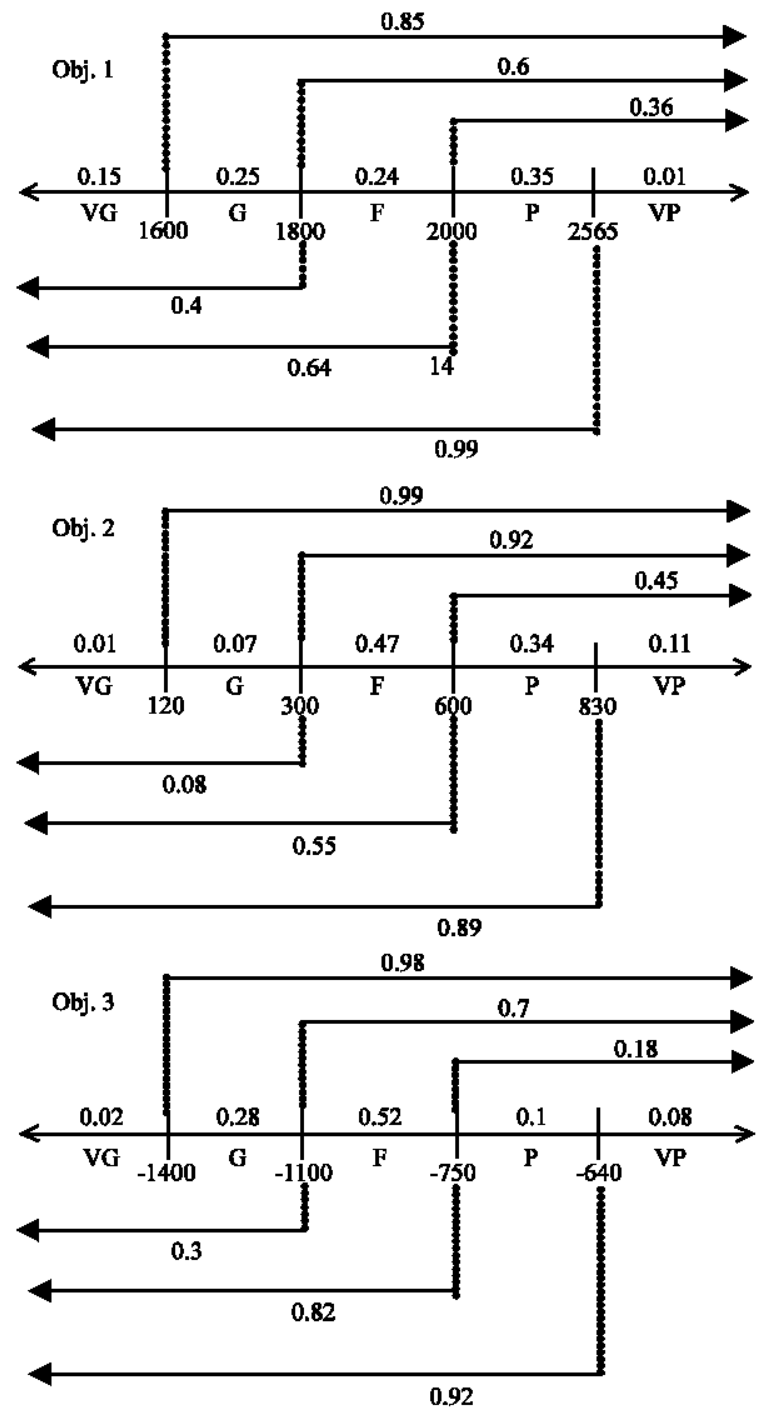

Fig. 4: Optimal solution of iteration 1

Objective 2:

$$
\mathrm{P}\left(\tilde{\mathrm{f}}_{2}(\mathrm{x}, \mathrm{c}) \leq 830\right) \geq 0.5
$$

Objective 3:

$$
\mathrm{P}\left(\tilde{\mathrm{f}}_{3}(\mathrm{x}, \mathrm{c}) \leq-640\right) \geq 0.5
$$

Given these values, problem 15 is solved and the optimal solution is $\mathrm{x}^{1}=(14.189,1.376,0,0,0,5.063,0.0783$, $15.098,2.525,18.429]^{\mathrm{T}}$ with the additional information shown in Fig. 4.

It can be seen that objective 1 has been improved, while objective 2 and 3 have become much worse, although the desired probabilities have not been achieved. Let us now suppose that the DM decides to set 


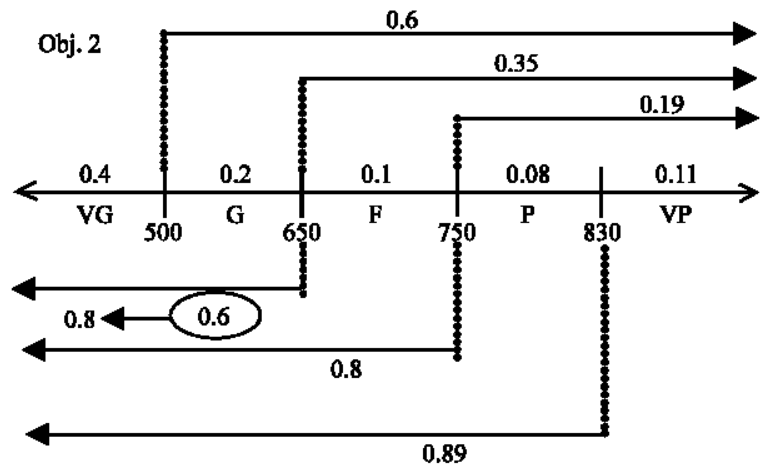

Fig. 5: New scale and probabilities for objective 2

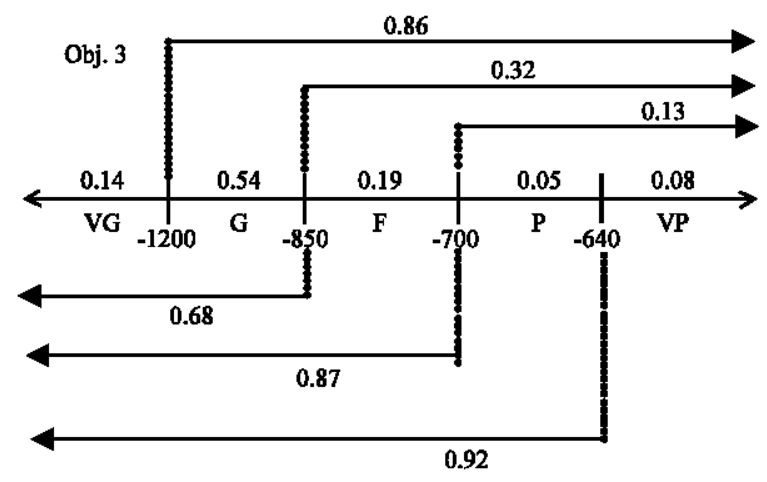

Fig. 6: New scale and probabilities for objective 3

a new (more realistic) scale for objective 2 and 3 . The new subintervals and the corresponding probabilities at the current solution are shown in Fig. 5 and 6.

After seeing the new values, the DM wishes to increase the probability for the second objective to be good and very good values by assigning the new probability:

\section{Objective 2:}

$$
\mathrm{P}\left(\tilde{\mathrm{f}}_{2}(\mathrm{x}, \mathrm{c}) \leq 650\right) \geq 0.8
$$

Given that no probabilities have been changed for the first and the third objective.

\section{Objective 1:}

$$
\mathrm{P}\left(\tilde{\mathrm{f}}_{1}(\mathrm{x}, \mathrm{c}) \leq \mathrm{u}_{1}^{1}\right) \geq 0.5
$$

Objective 3:

$$
\mathrm{P}\left(\tilde{\mathrm{f}}_{3}(\mathrm{x}, \mathrm{c}) \leq \mathrm{u}_{3}^{1}\right) \geq 0.5
$$

Iteration 2: The above relations are incorporated to problem 15. Its optimal solution $x^{2}=(14.5299,1.603,0,0,0$, $5.344,0.0899,14.86,2.234,18.262)^{\mathrm{T}}$. And the corresponding
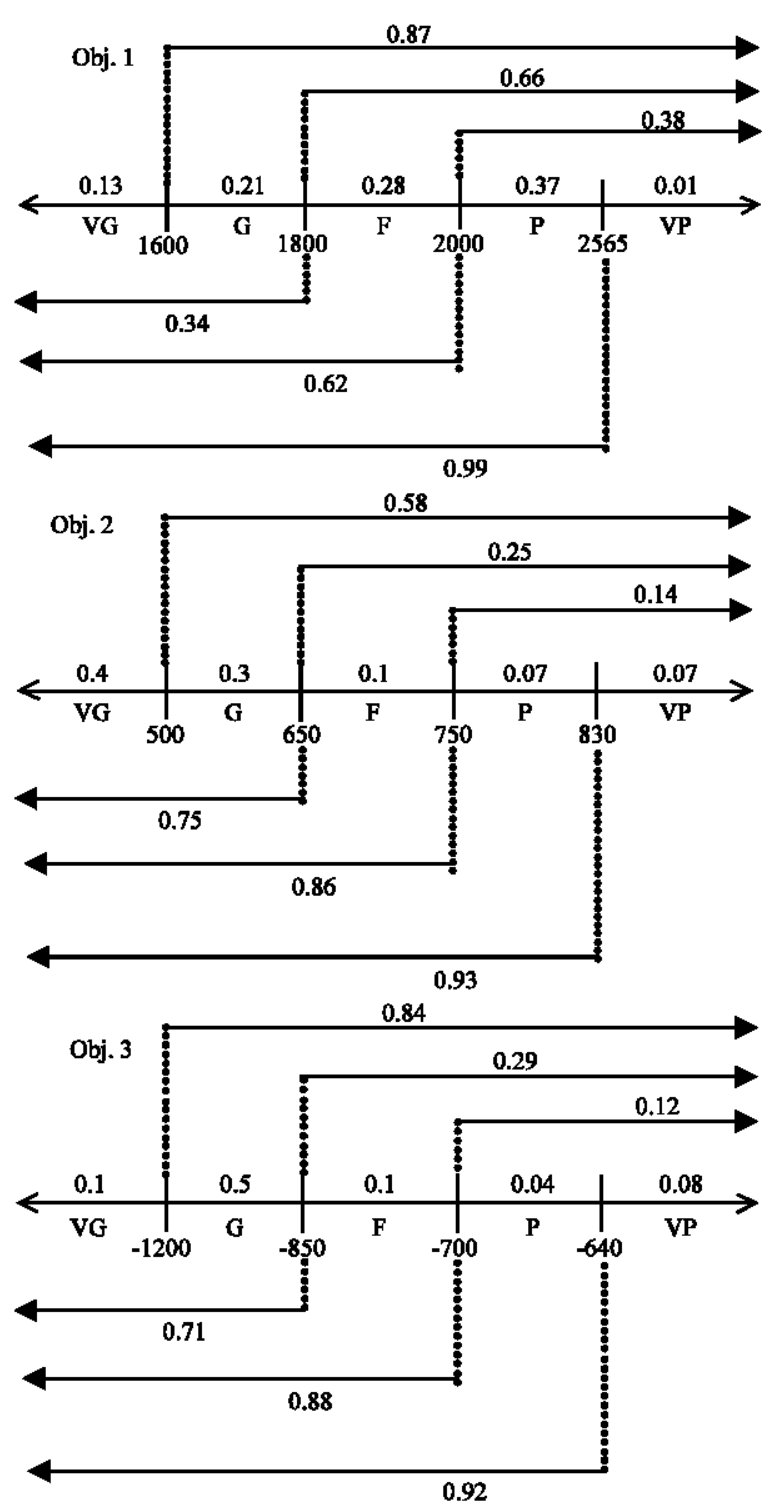

Fig. 7: Optimal solution of iteration 2

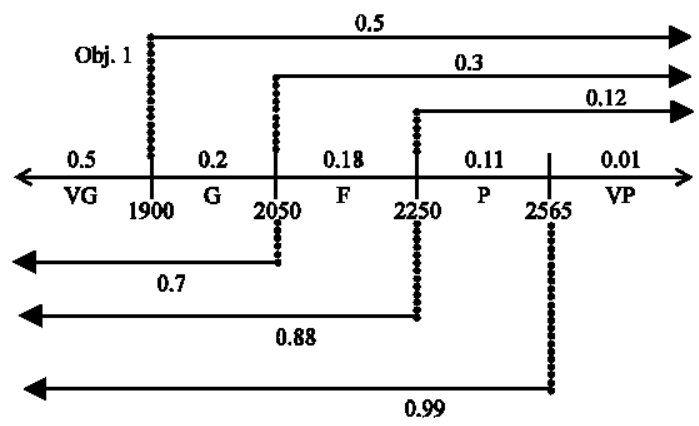

Fig. 8: New scale and probabilities for objective 1 
data are shown in Fig 7. Let us suppose that the DM decides now to change the scale of objective 1 and make it more realistic as well. The new scale and the corresponding probabilities at the current iteration are shown in Fig. 8.

\section{CONCLUSION}

In this study, we focused on multiobjective production planning problem involving random variable coefficients. After the formulation as the probability maximization model, we introduced stochastic goals to consider the ambiguous judgements of the decision maker and proposed an interactive stochastic approach based on reference point satisficing method as a fusion of stochastic approaches and deterministic ones to derive a satisficing solution for the decision maker from the efficient solutions obtained. The proposed approach enable the DM to learn in depth the features of the problem to evaluate the consequences of each decision and to know the trade-offs between the levels and the probabilities, inside each objective function and also among them. Among the different kinds of existing interactive methods for multiobjective problems, the ones based on the reference point scheme have proved to be particularly useful in order to favor the DM's learning process. The proposed approach is an extension research of Munoz and Ruiz (2009) with some modefications, where we aaproximate the stochastic variation range for each objective by applying the stochastic approach developed by Caballero et al. (2004) with any desired confidene interval assigned by the DM. The graphical representation of the probabilities associated to the different levels of the objective functions allows the DM to have a clear idea of the whole variation range of each function, as well as to understand the risk level that is assumed with each decision. Besides, the DM can modify the interval scales anytime and this fact, together with the elicitation of preferences in terms of probabilities makes the comparison among solutions easier and therefore, it facilitates the complex decision process within a random environment. This interactive method can be used to solve both linear and non-linear multiobjective problems with continuous random parameters. An application of production planning problem involving random variable coefficients in the objective function and constraints demonstrated the feasibility of the proposed method.

\section{REFERENCES}

Caballero, R., E. Cerda, M.M. Munoz and L. Rey, 2004. Stochastic approach versus multiobjective approach for obtaining efficient solutions in stochastic multiobjective programming problems. Eur. J. Operat. Res., 158: 633-648.
Chankong, V. and Y.Y. Haims, 1983. Multiobjective Decision Making: Theory and Methodology. Elsevier, North-Holland, Amsterdam.

Charnes, A. and W.W. Cooper, 1959. Chance-constrained programming. Manage. Sci., 6: 73-79.

Liu, B., 2008. Theory and Practice of Uncertain Programming. 3rd Edn., Uncertainty Theory Laboratory, Department of Mathematical Sciences Tsinghua University Beijing, China.

Liu, X. and Y. Tu, 2008. Production planning with limited inventory capacity and allowed stockout. Int. J. Prod. Econ., 111: 180-191.

Miettinen, K. and M.M. Makela, 2002. On scalarizing functions in multiobjective optimization. $\mathrm{OR}$ Spectrum, 24: 193-213.

Miettinen, K., 1999. Nonlinear Multiobjective Optimization. Kluwer Academic Publishers, Massachusetts.

Mula, J., R. Poler, J. Garca-Sabater and F. Lario, 2006. Models for production planning under uncertainty: A review. Int. J. Prod. Econ., 103: 271-285.

Munoz, M.M. and F. Ruiz, 2009. ISTMO: An interval reference point-based method for stochastic multiobjective programming problems. Eur. J. Operat. Res., 197: 25-35.

Prekopa, A., 1995. Stochastic Programming. Kluwer Academic Publishers, Dordrecht.

Slowinski, R. and J. Teghem, 1990. Stochastic Versus Fuzzy Approaches to Multiobjective Mathematical Programming under Uncertainty. Kluwer Academic Publishers, Dordrecht, Boston, London.

Stancu-Minasian, I.M., 1984. Stochastic Programming with Multiple Objective Functions. D. Reidel Publishing Co., Dordrecht.

Thomas, R., 2002. A de novo programming model for optimal distribution network design in a supply chain. Center for Business and Economics, http://www.elmhurst. edu/ earls/fdc/grantaps/fdcth omas.doc.

Vincke, P., 1992. Multicriteria Decision-Aid. John Wiley and Sons Inc., Chichester.

Wierzbicki, A.P., 1977. Basic properties of scalarizing functionals for multiobjective optimization. Optimization, 8: 55-60.

Wierzbicki, A.P., 1980. The Use of Reference Objectives in Multiobjective Optimization. In: Multiple Criteria Decision Making Theory and Applications, Fandel, G. and T. Gal (Eds.). Springer-Verlag, Berlin, Heidelberg, pp: 468-486. 